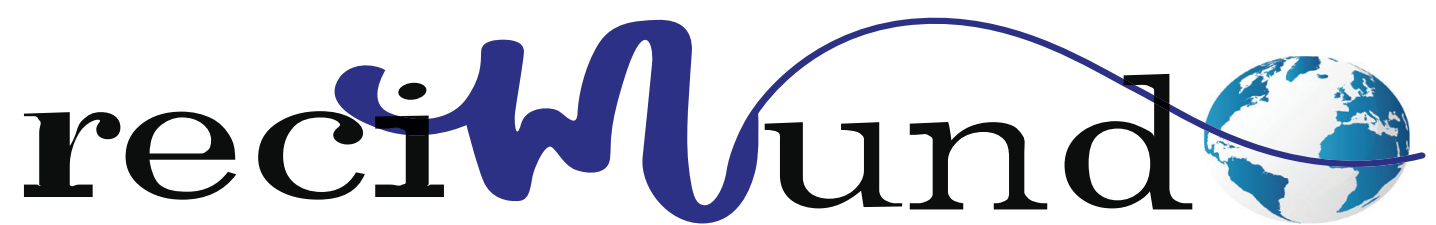

Revista Científica Mundo de la Investigación y el Conocimiento

DOI: 10.26820/recimundo/4.(4).octubre.2020.22-36

URL: http://recimundo.com/index.php/es/article/view/878

EDITORIAL: Saberes del Conocimiento

REVISTA: RECIMUNDO

ISSN: 2588-073X

TIPO DE INVESTIGACIÓN: Artículo de Revisión

CÓDIGO UNESCO: 23 Química; 2391 Química Ambiental

PAGINAS: 22-36

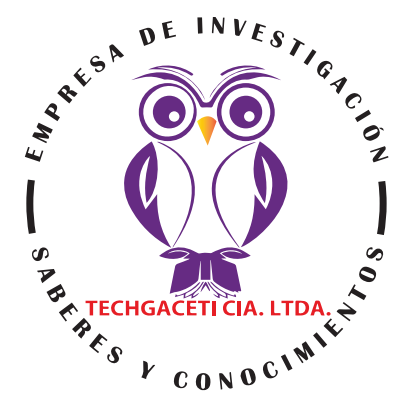

\title{
Desmineralización del agua como respuesta ante el cambio climático
}

Demineralization of water in response to climate change

Desmineralização da água em resposta às mudanças climáticas

Ana de las Mercedes Grijalva Endara'; María Elena Jiménez Heinert²; Henry Xavier Ponce Solórzano³

\section{RECIBIDO: 10/07/2020 ACEPTADO: 26/08/2020 PUBLICADO: 15/10/2020}

1. Magister en Cambio Climático; Magister en Auditoria de la Gestión de Calidad; Química Farmacéutica; Diploma Superior de Auditoria de Gestión de la Calidad; Docente de la Facultad de Ciencias Químicas; Universidad de Guayaquil; Guayaquil, Ecuador; ana.grijalvae@ug.edu.ec; iD https://orcid.org/0000-0003-2029-8601

2. Magister en Química Farmacéutica, Doctora en Químic y Farmacia, Químico Farmacéutico; Docente de la Universidad de Guayaquil; Guayaquil, Ecuador; marelejh@hotmail.com; (iD) https://orcid.org/0000-0003-3482-6233

3. Magister en Tecnología e Innovación Educatica, Ingeniero en Electrónica y Telecomunicaciones; Docente de la Universidad de Guayaquil; Guayaquil, Ecuador; henry.ponces@ug.edu.ec; iD https://orcid.org/0000-0003-4143-5863

\section{CORRESPONDENCIA}

Ana de las Mercedes Grijalva Endara

ana.grijalvae@ug.edu.ec

Guayaquil, Ecuador

(c) RECIMUNDO; Editorial Saberes del Conocimiento, 2020 


\section{RESUMEN}

El mundo se enfrenta a un incremento exponencial en problemas de disponibilidad de agua apta para el consumo humano como consecuencia del cambio climático motivado por el incremento de la temperatura en el planeta por efecto invernadero en la atmosfera que ha conllevado a grandes sequías, inundaciones y aumento del nivel del mar que pudieran estar afectando las composición química de las reservas de agua dulce, cercanos al eje costero. En base a esta problemática, la desalinización de agua salobre o de mar es una opción que podría resolver el problema planteado. En este artículo se revisan los principales procesos de tratamientos del agua y se analiza la factibilidad de la tecnología para tratar las aguas salobres y marina que garanticen de manera rentable, eficiente y sostenible el acceso al agua con la calidad y cantidad necesaria para la continuación de la vida en el planeta. Los resultados de dicha revisión documental permiten identificar que dentro de los procesos de desmineralización existe la tecnología que promete cumplir con las expectativas planteada como lo es la Osmosis Inversa pero que aun es necesario realizar mejoras para que pueda ser accesible y sostenible.

Palabras clave: Desmineralización, desalinización, osmosis inversa, agua potable, cambio climático.

\section{ABSTRACT}

The world is facing an exponential increase in problems of availability of water suitable for human consumption as a consequence of climate change caused by the increase in temperature on the planet due to the greenhouse effect in the atmosphere that has led to major droughts, floods and increased of the sea level that could be affecting the chemical composition of the fresh water reserves, near the coastal axis. Based on this problem, the desalination of brackish or sea water is an option that could solve the problem posed. This article reviews the main water treatment processes and analyzes the feasibility of technology to treat brackish and marine waters that guarantee in a profitable, efficient and sustainable way access to water with the quality and quantity necessary for the continuation of life on the planet. The results of said documentary review allow us to identify that within the demineralization processes there is a technology that promises to meet the expectations raised, such as Reverse Osmosis, but that improvements are still needed so that it can be accessible and sustainable.

Keywords: Demineralization, desalination, reverse osmosis, drinking water, climate change.

\section{RESUMO}

O mundo enfrenta um aumento exponencial dos problemas de disponibilidade de água adequada para o consumo humano em decorrência das mudanças climáticas provocadas pelo aumento da temperatura do planeta devido ao efeito estufa na atmosfera que tem gerado grandes secas, inundações e aumento do nível do mar que pode estar afetando a composição química das reservas de água doce, próximas ao eixo costeiro. Com base neste problema, a dessalinização da água salobra ou do mar é uma opção que pode resolver o problema apresentado. Este artigo revisa os principais processos de tratamento de água e analisa a viabilidade de tecnologia para tratar águas salobras e marinhas que garantam de forma rentável, eficiente e sustentável o acesso à água com a qualidade e quantidade necessárias à continuidade da vida no planeta. Os resultados da referida revisão documental permitem-nos identificar que nos processos de desmineralização existe uma tecnologia que promete responder às expectativas suscitadas, como a Osmose Reversa, mas que ainda são necessárias melhorias para que seja acessível e sustentável.

Palavras-chave: Desmineralização, dessalinização, osmose reversa, água potável, mudanças climáticas. 


\section{Introducción}

La retención de gases de efecto invernadero en la atmósfera que han originado el calentamiento global, según la Organización Meteorológica Mundial (OMM), es un hecho que la concentración atmosférica de CO2 alcanzó las 403,3 partes por millón (ppm), superando de nuevo la barrera de los 400 ppm y constituyendo el $145 \%$ de los niveles preindustriales de antes de 1750. Esta barrera de los 400 ppm se rebasó por primera vez en 2015, el año en el que se firmó el Acuerdo de París.

La emisiones de gases que incrementan el efecto invernadero a causa del cambio climático en su mayor parte son generadas por los países desarrollados, siendo sin embargo, los países más pobres del mundo donde se evidencia con mayor fuerza su impacto, con consecuencias traducidas en desalojos, pérdidas económicas y hasta muertes que aún no han servido para adoptar medidas urgentes en el cumplimiento de los compromisos adquiridos en Kioto (1997), referidos a las cuotas de emisiones o ejecutar las medidas de Copenhague (2009) para no superar el calentamiento en $2^{\circ} \mathrm{C}$.

Los modelos del cambio climático sugieren que en el próximo siglo nuestro planeta se calentará entre 1,4 y 5,8 grados centígrados, dependiendo de los niveles de emisiones de gas de efecto invernadero. Los cambios del clima afectarán tanto a la calidad como a la cantidad de agua disponible para los seres humanos y el medio ambiente. Los fenómenos climáticos extremos, como las inundaciones y las sequías, es probable que aumenten en intensidad y frecuencia. Se espera que el cambio climático afecte también a la calidad del agua de varias formas. Por lo tanto hay una necesidad clara de adaptarse a esta nueva realidad por medio del uso de nuevas técnicas.

El problema del cambio climático es com- plejo y difícil de atacar por parte de los ciudadanos, pero es determinante que la adaptación y hábitos sostenibles favorezcan los cambios progresivos en las comunidades mediante la consciencia de la nueva realidad, asumiendo nuevos hábitos en los consumos domésticos de agua y energía, así como medidas de eficiencia energética en las viviendas y con el uso del transporte público.

Uno de los sectores con mayor protagonismo a la hora de disminuir o hacer más soportable los efectos del cambio climático es el sector del agua. Son variados efectos del cambio climático referidos al agua, siendo las sequías una de las consecuencias más duras, más severas y frecuentes, la serie histórica nos confirma que cada vez incrementa su afectación en las zonas geográficas más secas, aumentando por tanto su extensión en tiempo y cantidad. En este mismo orden tenemos el aumento del nivel del mar por efecto del deshielo de las grandes masas y bloques de hielo tanto en los polos de ambos hemisferios como en los glaciales de los sistemas montañosos, junto con la intrusión de agua salina en los acuíferos en zonas costeras por la sobreexplotación de los mismos, incrementado la salinización de las reservas de agua dulce.

En este artículo nos centraremos en una de las soluciones tecnológica y medioambientalmente factible como lo es la desalación de las aguas y su utilidad para el uso doméstico e industrial, gracias a su tratamiento a través del proceso de desmineralización.

\section{Metodología}

La metodología utilizada se basó en la investigación bibliográfica documental mediante la revisión sistemática de bibliografía análisis e interpretación de literatura científico académica disponible.

Se selecciono la información de acuerdo a los criterios de pertinencia y correlatividad 
temática, en publicaciones, revistas, artículos académicos y científicos, originales, revisiones sistemáticas, protocolos, libros, boletines, folletos, tesis de posgrado y doctorado, noticias científicas, entre otros documentos e información de interés científico y académico.

En efecto, la revisión de estos contenidos bibliográficos, permite consolidar un análisis descriptivo sobre la desalinización y posterior desmineralización y potabilización de las aguas como alternativa ante el cambio climático que se vive en el planeta

\section{Resultados}

\section{El agua}

El agua obtenida mediante la extracción en distintos orígenes como ríos; pozos o mar, presentan distintas proporciones de sales minerales disueltas. Para lograr un valor óptimo de sales presentes en el agua y que esta sea adecuada para el uso tanto industrial como para el consumo humano, se hace uso de procesos físicos y químicos adaptados a la clase de agua cruda y a la calidad final que se requiere del agua tratada.

Los requerimientos de la calidad del agua varían de acuerdo con el uso, bien sea para la agricultura, la pesca, la propagación de vida silvestre, usos recreativos e industriales específicos o generación de energía. Algunas características del agua adecuadas para un fin pueden no serlo para otro. Es importante mencionar que los requerimientos de la calidad del agua, no se deben confundir con los estándares de calidad del agua. Los primeros están basados en la experiencia del uso y los segundos son cantidades establecidas por instituciones gubernamentales (Arellano, 2002)

Los Índices de Calidad del Agua (ICA) se definen como la evaluación de su naturaleza química, física y biológica en relación con la calidad natural, los efectos humanos y usos posibles. Para simplificar la interpretación de los datos de su monitoreo, existen Índices de Calidad de Agua (ICA) e Índices de Contaminación (ICO), estos reducen una gran cantidad de parámetros a una expresión simple de fácil interpretación entre técnicos, administradores ambientales y el público en general. La principal diferencia entre unos y otros está en la forma de evaluar los procesos de contaminación y el número de variables tenidas en cuenta en la formulación del índice respectivo.

En términos simples, un ICA es un número único que expresa la calidad del recurso hídrico mediante la integración de las mediciones de determinados parámetros de calidad del agua y su uso es cada vez más popular para identificar las tendencias integradas a los cambios en la calidad del agua (Torres, Cruz, y Patiño, 2009).

El agua para consumo humano proviene de dos tipos de fuentes:

- Las aguas superficiales y

- Las aguas subterráneas (también llamados acuíferos).

Las aguas superficiales, son las que se encuentran sobre la superficie de la tierra como los ríos, lagos y lagunas; en cuanto a las aguas subterráneas, ellas se encuentran en el subsuelo por filtración y son el resultado del ciclo hidrológico. El agua proveniente de estas fuentes, debe ser tratada para el consumo humano o de otra manera, la población en general sufriría de graves enfermedades.

Se define la contaminación del agua como la presencia de sustancias u organismos extraños en un cuerpo de agua en tal cantidad y con tales características que le impiden su utilización con propósitos determinados (Salamanca, 2016) ; ocurre por la acción de carácter antropogénica y la acción de la naturaleza, para lo cual existe dos tipos

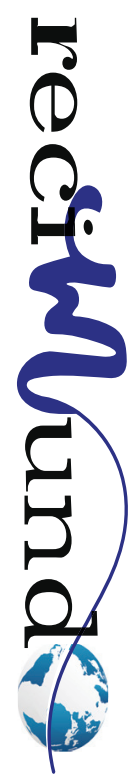


de tratamientos: el tratamiento de aguas residuales y el tratamiento de aguas para el consumo humano, este último lo analizaremos en este documento.

\section{Tratamiento del agua}

Históricamente, el agua se ha tratado con métodos muy sencillos como hirviéndola, exponiéndola al sol, sedimentándola o filtrándola a través de arena o grava para purificarla, para el consumo humano, estas han sido algunas de los métodos más antigua que se ha utilizado para disminuir y acabar con los residuos e impurezas, a su vez mejorar su aspecto físico ( olor, color, sabor y apariencia).

Hoy en día las técnicas de para el tratamiento de aguas con fines de consumo y que son ejecutados plantas de tratamiento, puede clasificarse en:

1. Procesos físicos,

2. Procesos químicos

3. Procesos biológicos

En torno a los procesos físicos se caracterizan por concentrar los contaminantes en evaporación o pasándola por elementos filtrantes. Entre estos destaca:

\begin{tabular}{ll} 
- & Filtración \\
- & Adsorción \\
- & Alocución \\
- & Clarificación \\
\hline
\end{tabular}

En efecto, la filtración permite remover partículas pequeñas mediante traspasar el agua a través material poroso para que sean retenidas en los espacios que hay en la superficie de los mismos. Este método, tal como lo señala (Salamanca, 2016) contribuye a "controlar la contaminación biológica y la turbiedad, que es la medida de la opacidad del agua causada por materia suspendida y que reduce la efectividad de los compuestos para su desinfección".
Ente las técnicas más usadas de filtración se encuentran:

- La Filtración lenta a rápida en lechos de arena.

- Sistemas de empaque para filtración.

En tal sentido los filtros se clasifican de acuerdo a la composición y material granular que usa, entre estos: carbón-antracita o arena-carbón; en función de si son filtros por gravedad o por presión. Los sistemas de filtración se clasifican por la dirección del flujo de agua a través del filtro, en flujo ascendente y descendente (Arellano, 2002).

La adsorción se genera a raíz de la atracción de determinada sustancia sobre la superficie de otra. Entre los componente de de adsorción que tienen mayor uso en el tratamiento del agua, son el carbón y la alúmina activados, ya que permiten remover arsénico y contaminantes orgánicos.

Al respecto cabe destacar que el uso del carbón activado ha sido usada con frecuencia a los fines de eliminar contaminantes ya que absorbe el material por su superficie y por que cada una de sus partículas contiene gran cantidad de poros donde éstas son retenidas y absorbidas; especialmente las sustancias orgánicas como los hidrocarburos. El carbón activado se utiliza en forma de polvo y granular. En forma de polvo es insoluble y de color negro y se usa para controlar sabor y olor, se agrega en cualquier etapa del tratamiento de aguas a través de filtros.

La alúmina activada es un alótropo del óxido de aluminio, en forma de material granular altamente poroso. En el tratamiento de aguas se utiliza para remover arsénico y exceso de iones de flúor. El procedimiento consiste en hacer pasar el agua a través de una columna rellena con este material, la remoción es una combinación entre adsorción con intercambio iónico. La utilización de la alúmina activada para remover arsé- 
nico e iones de flúor, requiere de periodos de regeneración. Cuando la alúmina se satura con arsénico y los iones de flúor, puede regenerarse haciendo pasar sosa cáustica $(\mathrm{NaOH})$ a través del material intercambio iónico. (Arellano, 2002).

En contraposición a los procesos físicos se encuentran los tratamientos químicos resultan nuevas sustancias. Se pueden mencionar:

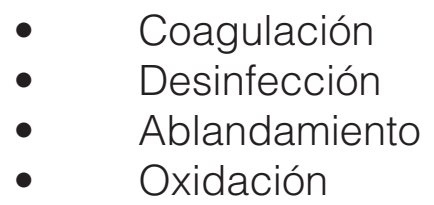

Los tratamientos biológicos puede ser visto como tratamientos químicos debido a que se usan organismos vivos para provocar cambios químicos, tales como:

\section{- $\quad$ Digestión aerobia \\ - Digestión anaerobia}

Aireación y oxidación: Refiere al proceso en donde el agua y el aire se ponen en contacto para la remoción de sustancias volátiles dentro y fuera del agua, como el oxígeno, bióxido de carbono, nitrógeno, sulfuro de hidrógeno, metano y otros compuestos que provoquen olores y sabores desagradables. Esta técnica es principalemente usada en aguas subterráneas por el alto contenido en concentraciones de bióxido de carbono, metano, sulfuro de hidrógeno, hierro y manganeso, con el objeto de precipitar los elementos.

En el tratamiento de aguas se usa la oxidación con diversos fines, ya que es una reacción en la cual las sustancias pierden electrones e incrementan su carga. Las sustancias oxidantes se utilizan para eliminar olores y sabores desagradables y clarificar el agua. Los oxidantes mas efectivos en el tratamiento de aguas son: el dióxido de cloro, el ozono y el permanganato de potasio y cloro de las cuales las más utilizadas son las dos últimas (Arellano, 2002).

Desinfección con cloro: Desde hace años, el cloro en diferentes combinaciones como ( $\mathrm{Ca}(\mathrm{ClO}) 2)$, líquido $(\mathrm{NaClO})$ o como gas (Cl2), se ha utilizado como desinfectante en diversos países (Arellano, 2002).

Desinfección con Ozono (O3) para desinfectar el agua requiere de un periodo de contacto más corto que el cloro para eliminarlos patógenos, es un gas tóxico que se puede obtener haciendo pasar el oxígeno que se encuentra en el aire a través de dos electrodos, es un compuesto inestable que puede ser generado en el mismo lugar donde se encuentra y tiene una baja solubilidad en el agua, por lo que se debe obtener la máxima eficiencia al estar en contacto con el líquido. Una desventaja que presenta es que debe utilizarse un desinfectante secundario, ya que éste no mantiene residuos en el agua, además de que su costo es muy elevado (Arellano, 2002).

Radiación ultravioleta (UV): es otro sistema utilizado y muy efectivo para eliminar las bacterias y virus, pero también necesita de un desinfectante secundario por las mismas razones que el ozono. La radiación ultravioleta es útil para sistemas pequeños de tratamiento de aguas porque tiene una disponibilidad inmediata, no produce residuos tóxicos, su tiempo para contacto es corto y su equipo es sencillo para operar y darle mantenimiento. Una desventaja importante de esta técnica es que no se puede utilizar para agua con altos niveles de sólidos suspendidos, turbiedad, color o materia orgánica, ya que las sustancias que generan estas propiedades pueden reaccionar o absorber la radiación ultravioleta reduciendo la eficiencia de la desinfección (Arellano, 2002).

Tratamiento de contaminantes orgánicos e inorgánicos: existen diferentes sustancias orgánicas sintéticas que se han depositado en las fuentes de abastecimiento de agua, 
algunas de ellas son el tricloroetileno que forma parte de los compuestos orgánicos volátiles (COV). Las fuentes de suministro han sido contaminadas por la disposición inadecuada de residuos, depósitos de gasolina, uso de insecticidas y efluentes industriales. La contaminación inorgánica en las fuentes de abastecimiento de agua se debe principalmente a las sustancias que se encuentran en forma natural en el agua como el arsénico, el bario, radón, azufre y selenio. La industria contribuye con el depósito de metales que se filtran en el subsuelo. Los químicos inorgánicos también se presentan en el agua potable debido a la corrosión, que es el deterioro o destrucción de los sistemas de bombeo y distribución de agua por la acción química o física, cuyo producto se deposita en el agua. Estos sistemas están hechos de metales como el plomo, cadmio, zinc, cobre y hierro liberados como productos de la corrosión y pueden causar problemas a la salud. La corrosión también puede afectar la vida útil de los sistemas de distribución y bombeo, proporcionando un campo de cultivo ideal para microorganismos que provocan sabores y olores desagradables. Para remover este tipo de contaminantes existen tecnologías tales como la coagulación, ósmosis inversa, intercambio iónico, alúmina activada y aereación, las cuales se discutirán en los siguientes apartados (Arellano, 2002).

El intercambio iónico se define como la transferencia de iones entre un medio sólido (resina) y una solución. Esta técnica es utilizada para remoción de cationes, lo que se conoce como ablandamiento. Como ya se había mencionado, la dureza del agua es causada principalmente por la presencia de iones de calcio y magnesio; también contribuyen el hierro, bario, aluminio y el estroncio. Las resinas utilizadas para intercambio iónico contienen elementos que intercambian iones de sodio. El lon hidronio está disponible en resinas, pero éste no es utilizado para ablandar aguas en fuentes de abastecimiento. Las resinas que gene- ran cationes de sodio reemplazan los iones que provocan la dureza, por lo que la disminuyen, pero incrementan el contenido de iones de sodio.

La desmineralización es un proceso de intercambio iónico que remueve los sólidos disueltos en las fuentes de suministro de agua. Estos sólidos disueltos contienen tanto aniones como cationes, por lo que requieren los dos tipos de resinas. Las resinas utilizadas con propósitos de desmineralización presentan intercambio de iones hidronio y se dividen en ácidos fuertes y ácidos débiles. Lo mismo sucede con los iones oxhidrilo que se dividen en bases fuertes y débiles. El agua blanda que se genera en este proceso, puede ser mezclada con otra con un mayor contenido de sales, para obtener la calidad del agua requerida en cuanto a su contenido de sales.

El proceso de desmineralización se utiliza para remover arsénico, bario, cadmio, cromo, flúor, plomo, mercurio, nitratos, selenio, plata, cobre, hierro, manganeso, sulfatos y zinc. Este proceso presenta muchas ventajas como son la baja inversión que se requiere y la simplicidad del proceso. Su mayor desventaja es el alto requerimiento químico para regenerar las resinas y disponer los residuos de estos procesos. Estos factores hacen que el intercambio iónico sea más adecuado para sistemas reducidos de tratamiento de agua. Los compuestos orgánicos disueltos, agentes oxidantes fuertes y sólidos suspendidos totales (SST) son contraproducentes en los sistemas de intercambio iónico. Los compuestos orgánicos pueden ser absorbidos en las resinas, el cloro pude ser removido por el carbón activado y los sólidos suspendidos pueden inhibir la transferencia de agua a través de la unidad de intercambio iónico y evitar así el contacto apropiado entre el agua y la resina de intercambio.

Procesos de membrana: existen dos tratamientos que involucran procesos de mem- 
brana y que son utilizados normalmente para remover sales (desmineralización) del agua: ósmosis inversa y electrodiálisis.

La ósmosis normal: dos soluciones que contienen diferentes concentraciones de minerales son separados por una membrana semipermeable. El agua se mueve a través de la membrana del lado donde la solución está más diluida hacia la parte de mayor concentración. Este fenómeno continúa hasta que la presión hidrostática en la solución de mayor concentración es suficiente para detener el flujo.

Ósmosis inversa: el flujo de agua que pasa a través de la membrana semipermeable es inverso por la aplicación de presión externa que contrarresta la presión hidrostática. Esto trae como resultado mayor concentración de minerales de un lado y menor concentración y agua pura en el otro lado.

Electrodiálisis: es la desmineralización de agua utilizando los principios de la ósmosis, pero con la influencia de un campo eléctrico de corriente directa. Los minerales se disocian en cationes y aniones cuando entra en el agua. El electrodo positivo llamado ánodo $(+)$, atrae los aniones y el electrodo negativo llamado cátodo (-), atrae los cationes. Existen dos tipos de membrana semipermeable selectiva utilizada en la electrodiálisis. Una que puede permear los cationes pero no los aniones y la otra puede permear los aniones pero no los cationes. Estas membranas se acomodan en capas, alternando las que permean cationes con las que permean aniones. El agua se alimenta en los espacios entre las membranas y se aplica un campo eléctrico de corriente directa entre las diferentes capas, lo que causa la migración de los iones hacia los electrodos opuestos y trae como consecuencia que los iones se concentren entre los espacios de membranas alternadas y en los demás espacios el agua desmineralizada, la cual es posteriormente extraída en diferentes chorros, uno que contiene los iones y el otro li- bre de los mismos.

El elemento esencial en el método de ósmosis inversa es la membrana semipermeable. Existen diferentes tipos de membranas semipermeables que serán utilizadas dependiendo de las características del agua que vaya a ser tratada. Los sólidos suspendidos, los disolventes orgánicos, el sulfuro de hidrógeno, el hierro, el manganeso y los agentes oxidantes pueden dañar las membranas. Las membranas de celulosa son susceptibles de ser atacadas por bacterias pero son resistentes al cloro. Las membranas de poliamida (nylon) no son blanco de ataques biológicos pero son sensibles al cloro. Por lo anterior, es necesario que el agua que entra a las unidades de electrodiálisis sea sometida a un tratamiento previo para eliminar los constituyentes indeseables. Se aconseja que el agua antes de este tipo de tratamiento tenga un pentre 5.0 y 6.5 para prevenir formación de hidróxidos y carbonatos, y que tenga niveles bajos de fierro y manganeso y agregar polifosfatos para inhibir la formación de sulfato de calcio (CaSO4).

Estabilización: El agua potable que salga de una planta de tratamiento y que entre al sistema de distribución debe estabilizarse. Esto significa que no debe formar depósitos de sales o ser corrosiva bajo las temperaturas en que será distribuida. La manera más común de ajustar el pH del agua es adicionando polifosfatos o silicatos. La estabilización del agua se asocia al ajuste del pH para controlar la corrosión; por lo que debe haber suficientes iones de calcio para que se forme carbonato de calcio. En el agua con esta última característica se debe agregar hidróxido de sodio para que no haya un incremento de la dureza (Arellano, 2002).

El agua usada en tratamientos proviene de varias fuentes de suministro, en particular las aguas subterráneas, de lagos y embalses contienen algunas sales, que se suelen denominar sales de dureza del agua, siendo las más comunes el calcio y el mag- 
nesio. Sin embargo, en muchos procesos existe la necesidad de reducir o eliminar en su totalidad estas sales de dureza. El término que se aplica para estos procesos es Desmineralización, el cual consiste básicamente en el filtrado de estos minerales. Las sales del agua se denominan sólidos disueltos y como tales requieren el uso de tecnologías para cambiar el estado de las sales del agua de soluble a insoluble y por consiguiente, extraíbles.

En numerosas aplicaciones de la industria, la calidad del agua debe ser pura para ser utilizadas en calderas, laboratorios y en muchos casos para la industria farmacéutica o textil, entre otras. Se considera agua pura aquella que está casi o completamente libre de minerales o sólidos disueltos, obteniéndose mediante los procesos de desmineralización, basado en la eliminación de iones inorgánicos presentes para obtener una alta calidad en el agua tratada.

\section{Agua desmineralizada su uso en el con- sumo humano y para la industria}

Aunque la tecnología tiene sus inicios en los años 60, la desmineralización no fue ampliamente utilizada hasta que algunos países centraron la investigación en este ámbito en el sector de salud pública, siendo en la antigua Unión Soviética donde fue presentada la desalación en la producción de agua potable para algunas ciudades de Asia Central. Desde el principio estuvo claro que el agua desalinizada o desmineralizada sin enriquecimiento de algunos minerales no podría ser totalmente adecuada para el consumo, debido a tres importantes razones:

- El agua desmineralizada es muy agresiva y si no es tratada antes no seria posible su distribución a través de tuberías y tanques de almacenamiento.

- Tiene la característica de tener mal gusto.

- Las pruebas preliminares que se dispo- nían, indicaban la presencia de sustancias que podrían causar efectos adversos a la salud humana.

Actualmente la desalinización procedente de agua de mar o agua salobre es una fuente de agua potable importante y de rápido crecimiento en el mundo. La composición mineral del agua es significativamente alterada y luego parcialmente reconstituida para lograr un producto estable que pueda ser distribuido en tuberías. Esta agua se diferencia de las aguas naturales en el sentido de que su composición es controlable mientras que las aguas naturales varían en un rango muy amplio de composición que es una cuestión de geología y azar.

El proceso de desalinización reduce significativamente todos los iones en el agua de beber, al punto que personas que tradicionalmente consumen agua desalinizada o agua destilada puede ser que estén recibiendo cantidades más pequeñas de algunos nutrientes comparado con personas que consumen agua de fuentes tradicionales y por lo tanto su dieta le perjudicará si no le proporciona suficientes nutrientes. Aunque, a veces, el agua desalinizada se estabiliza con la adición de algunos de estos iones. Es recomienda que el agua desmineralizada para el consumo humano contenga:

- Un nivel mínimo de sales disueltas (100 $\mathrm{mg} / \mathrm{L})$, bicarbonato ión (30 mg/L) y calcio (30 mg/L).

- Un nivel óptimo de sales disueltas totales (250-500 mg/L para cloruro-sulfato y 250-500 mg/L para bicarbonato).

- Un nivel máximo de alcalinidad (6.5 me$\mathrm{q} / \mathrm{l})$, sodio $(200 \mathrm{mg} / \mathrm{L})$, boro $(0.5 \mathrm{mg} / \mathrm{L})$ y bromo (0.01 mg/L).

El potencial efecto adverso en la de salud del consumo a largo plazo de agua desmineralizada es de interés no sólo en los países que carecen de agua fresca adecuada, también en países donde algunos tipos de 
sistemas caseros de tratamiento de agua son ampliamente utilizados o se consumen determinados tipos de agua embotellada.

El conocimiento de algunos efectos del consumo de agua desmineralizada está basado en datos experimentales que han sido obtenidos de poblaciones a las que se les suministra para beber agua desalinizada, particulares que consumen este tipo de agua y en niños que beben biberones preparados con agua destilada.

El agua desmineralizada es agua baja en sólidos disueltos, y que presenta baja conductividad eléctrica (medida en $\mu \mathrm{S} / \mathrm{cm}$ ). La ASTM D1193 Estándar de Especificaciones de Agua Tipo Reactivo (ASTM, American Society for Testing and Materials), clasifica al agua desmineralizada como: "un agua que contenga una conductividad eléctrica menor a 5 S/cm" (Carbotecnia, 2020).
Se divide en cuatro tipos, según su valor máximo permisible de conductividad eléctrica que determina su respectiva aplicación, según se detalla en la tabla $N^{\circ} 1$.

El agua completamente pura no es un buen conductor eléctrico, sin embargo en las aguas naturales se encuentran diversos sólidos disueltos que aportan iones con cargas positivas (cationes) y negativas (aniones), estos iones presentes en el agua permiten el paso de electricidad a través de ella. La concentración de los sólidos disueltos en el agua y la conductividad eléctrica son directamente proporcionales, esto quiere decir que al aumentar la concentración de sólidos disueltos aumenta la conductividad (Carbotecnia, 2020). La tabla \# 2 muestra los cationes y aniones más comunes que se encuentran en el agua natural.

Tabla 1. Tipos de agua desmineralizada

\begin{tabular}{|c|c|c|}
\hline $\begin{array}{c}\text { Tipo de agua } \\
\text { desmineralizada }\end{array}$ & $\begin{array}{c}\text { Valor máximo permisible de } \\
\text { conductividad eléctrica } \\
(\mu \mathrm{S} / \mathrm{cm})\end{array}$ & Aplicación típica \\
\hline Tipo IV & 5 & $\begin{array}{l}\text { - } \text { Agua embotellada } \\
\text { - } \quad \text { Calderas de alimentación de agua } \\
\text { - Industria de textiles } \\
\text { - Industria química } \\
\text { - } \text { Fábricas de cerveza } \\
\text { - } \quad \text { Agua potable } \\
\text { - } \quad \text { Fertilizóviles y bates } \\
\text { - } \\
\text { - Plantas industriales } \\
\text { - } \quad \text { Plantas de Energía } \\
\end{array}$ \\
\hline Tipo III & 1 & $\begin{array}{ll}\text { - } & \text { Cultivos de laboratorio } \\
\text { - } & \text { Enjuague de muestras analíticas de alta } \\
& \text { precisión } \\
\text { - } & \text { Preparación de muestras de referencia } \\
\text { - } & \text { Hospitales }\end{array}$ \\
\hline Tipo II & 0.5 & $\begin{array}{l}\text { - Industria farmacéutica } \\
\text { - Espectrometría de absorción atómica }\end{array}$ \\
\hline Tipo I & 0.055 & $\begin{array}{ll}\text { - Análisis de rastreo de metales } \\
\text { - }\end{array}$ \\
\hline
\end{tabular}

Fuente: (Carbotecnia, 2020) 
Tabla 2. Cationes y aniones más comunes en el agua natural

\begin{tabular}{|c|c|}
\hline Cationes $(+)$ & Aniones (-) \\
\hline Más comunes: & Más comunes: \\
$\mathbf{N a}^{+}$ & $\mathrm{Cl}^{-}$ \\
$\mathbf{C a}^{+2}$ & $\mathrm{HCO}_{3}^{-}$ \\
$\mathbf{M g}^{+2}$ & $\mathrm{CO}_{3}^{-}$ \\
Otros: & $\mathrm{SO}_{4}^{-2}$ \\
$\mathbf{F e}^{+2} \mathbf{F e}^{+3}$ & $\mathrm{PO}_{4}^{-2}$ \\
$\mathbf{P b}^{+2}$ & $\mathrm{SiO}_{2} \mathrm{HSiO}_{3}^{-}$ \\
$\mathbf{A l}^{+3}$ & Otros: \\
$\mathbf{B a}^{+2}$ & $\mathrm{~F}^{-}$ \\
& $\mathrm{H}_{3} \mathrm{AsO}_{3}$ \\
\hline
\end{tabular}

Fuente: (Carbotecnia, 2020)

Existen diferentes procesos para obtener de agua desmineralizada, en la industria pueden encontrarse los siguientes:

- Intercambio iónico

- Filtración por membranas (ósmosis inversa)

- Destilación

- Electrodiálisis

- Electrodeionización (EDI)

\section{Desmineralización mediante resinas de intercambio iónico}

El proceso de desmineralización de agua por intercambio iónico, consiste en hacerla pasar a través de una cama de resina catiónica (cargada de iones $\mathrm{H}+$ ) y una aniónica (cargada de iones $\mathrm{OH}-$ ), o una sola cama con ambas (resina mixta). Las resinas se clasifican en cuatro principales grupos, de acuerdo con los grupos funcionales unidos que se encuentran unidos a su matriz polimérica, son los siguientes:

- Catión de ácido fuerte (SAC)

- Catión de ácido débil (WAC)

- Anión de base fuerte (SBA)

- Anión de base débil (WBA)

El diseño de sistemas de intercambio iónico dependerá de la química del agua (se recomienda un estudio completo de aniones y cationes), que determina la combinación de resinas más efectiva, para un sistema de desmineralización (Carbotecnia, 2020).

Desmineralización por ósmosis inversa $(\mathrm{OI})$ La ósmosis inversa consiste en hacer pasar agua a través de una membrana semipermeable a una presión diferencial elevada (que supere la presión osmótica); de manera que los sólidos disueltos se concentran de un lado de la membrana (rechazo) y del otro lado un agua con una baja concentración de estos (producto). La calidad del agua producto dependerá de la alimentación y de la especificación del porcentaje de rechazo de sales de la membrana. Los sistemas de Ol permiten diseñar diferentes configuraciones, ya sea para obtener una mejor calidad de agua producto, para aumentar el volumen producción o para reducir el volumen de rechazo (Carbotecnia, 2020).

\section{Desmineralización por destilación}

La desmineralización por destilación, es la purificación química y biológica del agua a través de la vaporización térmica y su condensación. Los sistemas de destilación de agua no requieren demasiados controles en el agua de alimentación, sin embargo se debe tener especial cuidado con el arrastre de impurezas y con las variaciones de calidad del condensado (Carbotecnia, 2020). Desmineralización por electrodiálisis 
La electrodiálisis es un proceso de purificación, en el cual el agua se hace fluir a través de membranas ión-selectivas catiónicas y aniónicas, colocadas alternadamente, en una cámara llamada batería o acumulador, que suministra una corriente eléctrica para el flujo de los iones a través de las membranas. Los iones son transportados de una solución diluida a una solución concentrada (Carbotecnia, 2020).

\section{Desmineralización por Electrodeioniza- ción (EDI)}

Los sistemas de electrodeionización (EDI) usan una combinación de resinas, membranas ión-selectivas y cargas eléctricas para obtener agua con un alto grado de pureza (hasta $18.2 \mathrm{M} \Omega / \mathrm{cm}$ ) y que además está en regeneración continua. Consiste en pasar el agua a través de cámaras de resinas delimitadas por membranas ión-selectivas. La resina actúa como un conductor permitiendo que la corriente eléctrica desplace los aniones y cationes capturados en la resina, los cuales son concentrados y expulsados del sistema en el flujo de rechazo. Al mismo tiempo, la corriente eléctrica separa el agua en iones hidrógeno $(\mathrm{H}+)$ e hidroxilo $(\mathrm{OH}-)$ que permiten la regeneración continúa de la resina sin la necesidad de utilizar químicos regenerantes (Carbotecnia, 2020).

\section{Agua Desalinizada:}

La desalinización consiste en un proceso de separación de sales disueltas de aguas salobres ó de mar para convertirlas en aguas adecuadas para consumo humano, uso industrial ó riegos (Medina, 2000).

En la década de 1950 se inician las primeras investigaciones sobre desalinización, con el objeto de construir grandes instalaciones de producción de agua dulce, y se obtienen resultados importantes como el sistema de destilación súbita flash en múltiples etapas en 1957, lo que permite construir la primera planta comercial en 1960 (Custodio, 1976).
Actualmente, el agua desalinizada se utiliza para consumo humano, en procesos industriales y en forma muy limitada para riego agrícola, pues los costos de desalinizar agua son relativamente altos para usar este líquido con los métodos tradicionales de riego; resulta más económico importar los productos agrícolas de aquellos países que cuentan con las condiciones climatológicas adecuadas para producirlas.

Existen diversas tecnologías desarrolladas actualmente para desalinizar el agua de mar y aunque tienen características distintas de acuerdo al tipo de energía, diseño y producción que requiere cada una, todas tienen el mismo objetivo, reducir la concentración de sales disueltas del agua de mar, esto permite distinguir entre los procesos que separan el agua de las sales y los que realmente efectúan la separación de las sales de la solución (tabla №3). 
Tabla 3. Clasificación de los procesos de desalinización

\begin{tabular}{|c|c|c|c|}
\hline $\begin{array}{l}\text { Clase de } \\
\text { separación }\end{array}$ & Energía utilizada & Proceso & Sistema \\
\hline \multirow[t]{2}{*}{$\begin{array}{c}\text { Separación agua } \\
\text { de sales }\end{array}$} & Vapor & Evaporación & $\begin{array}{l}\text { - Destilación solar } \\
\text { - Destilación súbita simple } \\
\text { - Destilación en tubos sumergidos } \\
\text { - Destilación súbita multietapa } \\
\text { - Destilación multiefecto de tubos } \\
\text { horizontales } \\
\text { - Destilación multiefecto de tubos } \\
\text { verticales } \\
\text { - Compresión mecánica de vapor } \\
\text { - Termo compresión de vapor }\end{array}$ \\
\hline & Frío & Cristalización & $\begin{array}{l}\text { - Formación de hidratos } \\
\text { - Congelación }\end{array}$ \\
\hline \multirow{3}{*}{$\begin{array}{l}\text { Separación de } \\
\text { sales del agua }\end{array}$} & Presión & Membrana & - Ósmosis Inversa \\
\hline & Carga eléctrica & Membrana selectiva & - Electrodiálisis \\
\hline & Atracción química & Membrana selectiva & - Intercambio iónico \\
\hline
\end{tabular}

\section{Fuente: Los autores}

La disponibilidad de agua no implica que su calidad permita el uso, la contaminación natural y el hombre ha provocado que sea necesario tratarla antes de destinarla a consumo humano, agrícola e industrial. La calidad del agua varía acorde a la región y por el tipo de subsuelo de los contaminantes (tabla $N^{\circ} 4$ ).

Tabla 4. Calinidad de diferentes tipos de agua

\begin{tabular}{|l|r|}
\multicolumn{2}{|c|}{ Agua } \\
\hline Ultrapura & 0.03 \\
\hline Pura & 0.30 \\
\hline Desionizada & 3.00 \\
\hline Potable & $<1,000.00$ \\
\hline Salobre & $1,000.00-10,000.00$ \\
\hline Salina & $10,000.00-30,000.00$ \\
\hline Marina & $30,000.00-50,000.00$ \\
\hline
\end{tabular}

Fuente: Valero (2001)

El agua obtenida de los procesos de desalinización es perfectamente utilizable en la agricultura, turismo y consumo humano, pero exigen una eliminación más selectiva de iones.

Estudios de la factibilidad de costos y con- sumo energético ha demostrado que el tipo de tecnología que requiere menor consumo energético es la osmosis inversa, presentando ventajas significativas sobre el resto de los procesos, debido a que esta tecnología no requiere de cambios de estado, como los usados en procesos de destilación 
multiefecto y destilación súbita multietapa, que utilizan mayor consumo energético e incrementan la emisión de CO2, provocando el efecto invernadero, y los terribles daños en la atmósfera, ocasionando problemas medioambientales, que todos padecen, y que se han ido incrementando con el tiempo, por agotamiento de los recursos y sobrepoblación en la Tierra (Lechuga, 2007). La ósmosis inversa, además de requerir el menor consumo energético y puede utilizar agua salobre como de mar, una ventaja ante los sistemas térmicos. El costo de inversión es ligado a las características del agua que se pretende desalar y en general es inferior respecto a los sistemas térmicos. En este proceso es indispensable el uso de tratamientos fisicoquímicos que suelen ser muy importantes y claves para elevar el tiempo de vida de las membranas. El terreno en extensión es de tipo medio. Necesita una fuente exterior de energía para operar las bombas de alta presión. Por otro lado la presencia de iones específicos limita sus posibilidades de aplicación eficiente y su manejo se complica en función de las características fisicoquímicos del agua.

\section{Conclusión}

En la actualidad el mundo apuesta por la desalinización como posible solución a los problemas de cantidad y la calidad del agua, los cuales empeorarán con el crecimiento global de la población, el calor extremo y la sequía prolongada vinculada al cambio climático. Esta solución tecnológicamente es posible mediante los actuales procesos de desmineralización, entre los que destaca la tecnología de la osmosis inversa que en los últimos 50 años se ha venido perfeccionando y solucionando problemas en cuanto el impacto al ambiente, requerimientos de energía y rentabilidad. Para hacerla mas accesible y costeable, los investigadores continúan estudiando las mejoras en la durabilidad y eficacia de las membranas, que permitan producir mas agua por unidad de energía; el uso de fuentes de energía reno- vables y en mejoras en las formas de manejar el efluente tipo salmuera dejado por este proceso.

La calidad del agua que se libra al consumo es uno de los aspectos que siempre debe ser motivo de preocupación para las autoridades que trabajan en el campo del agua potable, no solamente bajo la óptica de que obligatoriamente deben cumplirse los reglamentos que regulan en la materia, sino pensando además en brindar a la población un producto sano y saludable, vital para el desarrollo de todas las actividades humanas. La calidad del agua y su acceso es un problema evidente, debido a que la cantidad del recurso hídrico es limitada, de ahí que se tenga que potabilizar aguas residuales y servidas.

\section{Bibliografía}

Arellano, J. (2002). Introducción a la Ingeniería Ambiental. México D.F, México: Alfaomega.

Canto, J. (1977). Tratamiento de Aguas para Abastecimiento Publico. Barcelona, España: Técnicos Asociados.

Carbotecnia. (2020). Agua desmineralizada. Obtenido de https://www.carbotecnia.info/ aprendizaje/ tratamiento-de-agua/que-es-el-agua-desmineralizada/\#: :text=Consiste \%20en \%20pasar \%20 el\%20agua,en\%20el\%20flujo\%20de\%20rechazo.

Custodio E., L. M. (1976). Hidrología subterránea. 2. Barcelona, España: Ediciones Omega.

Dévora Isiordia, G. E., González Enríquez, R., \& Ponce Fernández, N. E. (Mayo-Agosto de 2012). TÉCNICAS PARA DESALINIZAR AGUA DE MAR Y SU DESARROLLO EN MÉXICO. Universidad Autónoma Indígena de México, 8(2).

Lechuga, J. (2007). Análisis de los procesos para desalinización de agua de mar aplicando la inteligencia competitiva y tecnológica. Revista Académica de la FIUADY, 5-14.

Medina, J. (2000). Desalinización de aguas salobres y de mar en ósmosis inversa. 779. Madrid, España: Editorial Mundi Prensa.

Rios, D. (2012). Riesgos biológicos y subproductos de la desinfección en el agua de bebida. Obtenido de http://www.bvsde.paho.org/ bvsacd/cd59/ danilorios.pdf 


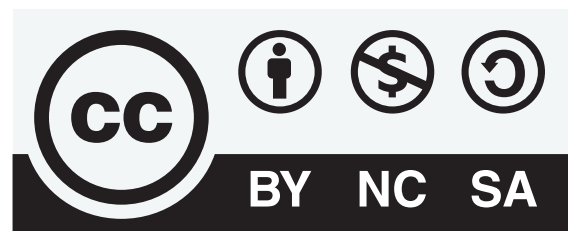

CREATIVE COMMONS RECONOCIMIENTO-NOCOMERCIAL-COMPARTIRIGUAL 4.0.

\section{CITAR ESTE ARTICULO:}

Grijalva Endara, A., Jiménez Heinert, M., \& Ponce Solórzano, H. (2020). Desmineralización del agua como respuesta ante el cambio climático. RECIMUNDO, 4(4), 22-36. doi:10.26820/recimundo/4.(4).octubre.2020.22-36 